\title{
Community Causes of Death in the Central Region of Ghana, the Missing Piece in Mortality Data
}

\author{
Patrick Kafui Akakpo (i), ${ }^{1}$ Emmanuel Gustav Imbeah $\mathbb{D}^{1},{ }^{1}$ Francis Agyarko-Wiredu, ${ }^{1}$ \\ Kennedy Awlavi, ${ }^{1}$ Kwame Baah-Amoh, ${ }^{2}$ and Leonard Derkyi-Kwarteng ${ }^{1}$ \\ ${ }^{1}$ Department of Pathology, School of Medical Sciences, University of Cape Coast, Cape Coast Teaching Hospital, \\ Cape Coast, Ghana \\ ${ }^{2}$ Department of Community Medicine, School of Medical Sciences, University of Cape Coast, Cape Coast Teaching Hospital, \\ Cape Coast, Ghana
}

Correspondence should be addressed to Patrick Kafui Akakpo; k.p.akakpo@uccsms.edu.gh

Received 20 February 2020; Accepted 13 April 2020; Published 29 April 2020

Academic Editor: Carol J. Burns

Copyright (C) 2020 Patrick Kafui Akakpo et al. This is an open access article distributed under the Creative Commons Attribution License, which permits unrestricted use, distribution, and reproduction in any medium, provided the original work is properly cited.

\begin{abstract}
Objective. Mortality data from hospitals in Ghana suggest a changing mortality trend with noncommunicable diseases (cardiovascular disorders) replacing communicable diseases as the leading cause of death. Our objective was to find out the causes of deaths in the communities of the Central Region of Ghana and raise awareness of these causes of deaths while highlighting the differences that exist between data obtained from the community and that obtained from the hospital. Method. Mortality data from Coroner's autopsies mostly provide data about the causes of deaths in the community (out of hospital). A retrospective descriptive study of Coroner's autopsy data at the Cape Coast Teaching Hospital was carried out over a six-year period. The various causes of death were categorized according to broad headings (accidents/injuries/poisoning, cardiovascular, infections, metabolic, neoplasms, and others). Results. A total of 1187 autopsies were reviewed of which 990 (83.4\%) were Coroner's cases. Of these Coroner's cases, 719 (72.6\%) were male and 271 (27.4\%) were female. 521 (52.6\%) of victims were young adults (18-44 years), and majority of deaths were unnatural (due to accidents, injuries, and poisoning) (64.1\%), followed by the general category of others (15.3\%). Cardiovascular deaths (6.6\%) were fourth after infections $(9.8 \%)$. In the leading category, most deaths were due to road traffic accidents (50.4\%) as occupants of vehicles and motorcycles (28.7\%) and as pedestrians (21.7\%). Deaths due to road traffic accidents were followed by deaths due to drowning (14.96\%). Conclusion. Although noncommunicable diseases are still the leading causes of death outside the hospital, most of the deaths are due to road traffic accidents and drowning. This is at variance with hospital data that suggest that the leading noncommunicable diseases are cardiovascular disorders and cancer. Again, like data derived from hospitals, infections remain a major cause of death in the Central Region of Ghana. Studies combining the causes of death derived from Coroner's autopsies and communities and from medical certificates of cause of death will present a better picture of the leading causes of death in the Central Region and reveal the true nature of noncommunicable diseases that currently form our largest disease burden.
\end{abstract}

\section{Introduction}

The World Health Organization defined cause of death as "all those diseases, morbid conditions, or injuries which either resulted in or contributed to death and the circumstances of the accident or violence which produced any such fatal injuries" [1]. Policies aimed at tackling the underlying cause of death achieve the most positive effect on health outcomes. To determine the cause of a death in the community outside the hospital, an autopsy is ordered by the Coroner within the magisterial district within which a person dies. These autopsies are designated as Coroner's (medicolegal) cases. Deaths investigated through this mandate may turn out to be natural (solely due to diseases or disease processes) or unnatural (due to accidents, injuries, and poisoning whose manner may be accidental, homicidal, 
or suicidal). Autopsies requested in hospitals are designated clinical/permission autopsies and are done to study disease processes. In this regard, Coroner's cases are a representation of mainly deaths occurring in the communities and of suspicious or unnatural deaths occurring in hospitals [1]. Deaths of this nature are not signed out with Medical Certificates of Cause of Death (MCCD). Instead, they are signed out on Coroner's mandate forms, and thus, these statistics may not be readily available to researchers conducting research on hospital deaths.

Ghana, like other countries, has established legislation that guides civil and vital registration systems to collect and collate statistics on deaths and their cause. Cause of death data are however not always accurate since they are more likely to be obtained mainly from health facilities, since these facilities have medical certificates of cause of death completed for every death that occurs. Worldwide, there have been commendable efforts aimed at improving the quality of such data through initiatives such as "data for health" [2]. Reflecting the source of most data in Ghana, malaria has been a leading cause of death together with lower respiratory tract infections, neonatal infections, ischemic heart disease, stroke, HIV/AIDS, and tuberculosis. Road injuries are 9th on the list in one publication by the Centre for Disease Control (CDC) in 2019 [3]. Many deaths however occur in the communities with a fraction being reported to the Coroner for autopsy. Those that are autopsied have their data available at autopsy suites and ultimately at the Births and Deaths registry where deaths are finally registered. Data regarding the circumstances of such deaths are largely dependent on the quality of entries. This means that hospitalderived data that do not include data from autopsy suites fail to capture a significant number of deaths occurring in the community. The deaths that occur within the community that are not reported to the Coroner mostly end up not being registered and thus are also not available for registration, further compromising quality of death statistics. Concerning mortality data, after an analysis of the pattern of death in Ghana, the Ghana Statistical Service during the last population census in 2010 reported that there is substantial underreporting of deaths, especially in adult ages. Their assessment of the quality of mortality data collected in Ghana showed evidence of reporting bias and errors [4]. In the Central Region of Ghana where autopsies can only be done in the Cape Coast metropolis, a significant proportion of community deaths go unreported, and even for community deaths that are treated as Coroner's cases and autopsied, hospital mortality statistics based on signed medical certificates of cause of death will not capture these community causes of death.

Many low- and middle-income countries are unable to obtain high-quality civil and vital statistics due partly to the incompleteness of data collected [5]. The result is that the policy value of such statistics is reduced. This is notwithstanding the fact that standard methods proven to work in high-income nations have been applied to the collection of civil and vital statistics from such middle- and low-income countries [5]. Between 2000 and 2015, the completeness of global death registration statistics is reported to have increased from only 36.2 to $38.6 \%$ [6]. Among other things, this state of affairs has been attributed to "inefficient methods of data collection" [5]. The planned achievement of the UN sustainable development goals may be hampered by the global lack of reliable and accurate mortality data which form an essential part of health planning and epidemiology research [7].

Our aim is to draw attention to the variation in mortality data from different sources within the Central Region of Ghana. Through this, we hope that the negative effects of poor quality civil and vital statistics will be highlighted; we advocate for increased effort to include data from all sources in regional and national civil and vital statistics to improve quality and optimize the benefits derived from such statistics.

\section{Methodology}

The study was carried out at the Department of Pathology of the Cape Coast Teaching Hospital (CCTH). The department serves the Central Region and its neighboring communities, extending into the Western Region. A retrospective study of all autopsies conducted in the department from January 2011 to December 2016 was carried out.

2.1. Inclusion Criteria. All Coroners' cases done and properly recorded in the autopsy record book between January 2011 and December 2016 were included. Cases with incomplete information were excluded.

2.2. Data Collection and Analysis. Data were collected from the autopsy record book of the Department of Pathology. It was analyzed using Microsoft Excel ${ }^{\circledR} 2010$ software and statistical package for social sciences (SPSS) version 20. The underlying causes of death of all Coroner's cases were grouped into seven main categories as follows: natural causes (infectious causes, cardiovascular causes, pregnancy-related causes, metabolic causes, tumours, and others) and unnatural causes (accidents, injuries, and poisoning). These were correlated with age and sex.

2.3. Ethical Clearance. Ethical clearance was sought through the Department of Community Medicine, School of Medical Sciences, University of Cape Coast. In addition, institutional accent was obtained from the Cape Coast Teaching Hospital.

\section{Results}

A total of 1187 autopsies were performed during the study period, of which 990 (83.4\%) were Coroner's autopsies. 197 (16.6\%) were hospital autopsies (Table 1). Of the 990 Coroner's autopsies, $719(72.6 \%)$ were male, while $271(27.4 \%)$ were female. Most (52.6\%) of the victims were young adults (18-44 yrs), followed by the middle-aged (45-64 yrs) (23.5\%), children (13 months (mo.)-17yrs) (15.05\%), and the elderly ( $\geq 65 \mathrm{yrs})$ (7.9\%) (Table 2 ).

Majority (64.14\%) of deaths were due to accidents, injuries, and poisoning, followed by others (15.25\%). 
TABLE 1: Frequencies of underlying causes of death in the communities.

\begin{tabular}{lcc}
\hline Underlying cause of death & Number & $\%$ \\
\hline Accidents/injuries/poisoning & 635 & 64.141 \\
Others & 151 & 15.252 \\
Infections & 97 & 9.798 \\
Cardiovascular diseases & 65 & 6.566 \\
Malignancies & 23 & 2.323 \\
Pregnancy-related & 15 & 1.515 \\
Metabolic disorders & 4 & 0.404 \\
Total & 990 & 100.00 \\
\hline
\end{tabular}

TABLE 2: Age distribution of Coroner's cases and their gender.

\begin{tabular}{lcccc}
\hline Age distribution of Coroner's case & Male & Female & Total & $\%$ \\
\hline Neonate (<1 months) & 2 & 1 & 3 & 0.30 \\
Infant (1 month-1 yr) & 2 & 4 & 6 & 0.61 \\
Child (13 months-17 yrs) & 93 & 56 & 149 & 15.05 \\
Young adult (18 yrs-44 yrs) & 389 & 132 & 521 & 52.63 \\
Middle-aged ( 45 yrs-64 yrs) & 179 & 54 & 233 & 23.54 \\
Elderly ( $\geq 65$ yrs $)$ & 54 & 24 & 78 & 7.88 \\
Total & 719 & 271 & 990 & 100.00 \\
\hline
\end{tabular}

Cardiovascular deaths (6.56\%) were 4th after infections (9.80\%). Pregnancy-related deaths were 6th $(1.52 \%)$ after tumours $(2.32 \%)$, with metabolic causes $(0.40 \%)$ being the least (Table 1). Most of the accident/injury/poisoning deaths were due to road traffic accidents (RTA) $(50.39 \%)$ as pedestrians $(21.73 \%)$, passengers $(16.53 \%)$, drivers $(5.98 \%)$, and other road users such bike riders (6.14\%). Road traffic accident deaths were followed by deaths due to drowning $(14.96 \%)$ and then assaults, blunt head trauma, chest and abdominal injuries (7.56\%), gunshot injuries (5.35\%), and hanging $(4.88 \%)$ (Table 3$)$.

In the "other" causes of death category, 30 (19.87\%) persons died of systemic congestion (suspected poisonings with toxicology pending) while the causes of death were unascertained because of advanced decomposition in $41(27.15 \%)$ cases over the 6 years. Hypertensive heart diseases accounted for $52(80.00 \%)$ of deaths due to cardiovascular disease, followed by coronary artery disease $(7.69 \%)$.

\section{Discussion}

A total of 1187 autopsies were performed during the study period out of which 990 (83.4\%) were Coroner's (medicolegal) cases with death occurring in the communities; 197 (16.6\%) were hospital autopsies. The proportion of Coroner's (medicolegal) autopsies is much higher in our study compared to a study in Ibadan, Nigeria, where the proportion of Coroner's autopsies was $62.5 \%$ [8]. Majority of the cases in this study were male $(72.6 \%)$ while females constituted $27.4 \%$ of the cases autopsied. This gives a ratio of 2.6:1 suggesting that a lot more males are dying in the communities compared to females. This is comparable to studies in Nigeria, Ibadan $(1.7: 1)$ and Benin City $(2.6: 1)$ $[8,9]$.
Majority (64.14\%) of deaths were unnatural and due to the broad category of accidents, injuries, and poisoning, followed by the broad category of "others" (15.25\%), which includes deaths for which the causes were unascertained. Cardiovascular deaths were fourth $(6.57 \%)$ after infections $(9.80 \%)$ as a group. Pregnancy-related deaths were sixth (1.51\%) after tumours (2.32\%). These findings are at variance with the study in Ibadan in which the most common indications for Coroner's autopsies were sudden natural deaths (55.6\%), followed by accidental deaths (35.3\%). The proportion of maternal death (4.3\%) was much higher in the study in Ibadan [8]. Though these findings suggest that noncommunicable diseases are the leading cause of deaths in the communities of the Central Region of Ghana, in line with global reports from the global burden of diseases assessments that suggest an obvious transition toward noncommunicable diseases being the leading cause of death globally, the details suggest that majority of these deaths are due to injuries as opposed to cardiovascular diseases, in line with the global reports [6]. It has previously been reported however that the transition toward noncommunicable diseases being the leading cause of death seems not to be occurring in the sub-Saharan African region probably due to the poor quality of civil and vital statistics in this region [6]. Then again, even for many of those countries that have reported this transition, there seems to be a systematic misrepresentation or underestimation of the severity of deaths due to noncommunicable preventable causes and to injuries [6]. Our findings suggest that injuries may contribute significantly to the burden of noncommunicable diseases in Ghana and that measures should be put in place to capture these data in the community to guide policy. This will be in line with knowledge that "improving the health of populations requires knowledge about the leading causes of death of the typically, much larger fraction of deaths that occur at home, or in the community and for which relatively little is reliably known" [6].

The lower proportion of deaths due to natural causes in our study may be because these deaths are treated rightly as natural deaths and medical certificates of cause of death are signed for them. In a study conducted in the Benin City in Nigeria, the most common causes of sudden unexpected natural deaths were cardiovascular diseases resulting from complications of hypertension (54.7\%) [9]. This is again at variance with our study which showed that more people die from infections in the community as compared to cardiovascular-related deaths. It can be inferred from this finding that people in the communities of the Central Region are more likely to die from infections than from cardiovascular causes which came after infections as cause of death in this study. Concerning cardiovascular deaths, however, most deaths $(80 \%)$ were due to hypertensive heart disease, similar to findings in Nigeria [9].

In the general category of accidents, injuries, and poisoning, most of the deaths in this category were due to road traffic accidents $(50.39 \%)$ as pedestrians $(21.73 \%)$, passengers (16.54\%), drivers (5.98\%), and motorcycle riders (6.14\%). Our findings conform to a study in Kenya where pedestrians and passengers were the most vulnerable; they 
TABLE 3: Categories of underlying causes of deaths in the community.

\begin{tabular}{|c|c|c|c|c|c|c|c|c|}
\hline Underlying cause of death & $<1 \mathrm{mo}$ & $1 \mathrm{mo}-12 \mathrm{mo}$ & $13 \mathrm{mo}-17 \mathrm{yrs}$ & 18 yrs -44 yrs & 45 yrs -64 yrs & $\geq 65$ yrs & Total & $\%$ \\
\hline \multicolumn{9}{|l|}{ Accidents/injuries/poisoning } \\
\hline RTA pedestrian & 0 & 1 & 34 & 59 & 31 & 13 & 138 & 21.732 \\
\hline RTA passenger & 0 & 1 & 3 & 75 & 20 & 6 & 105 & 16.535 \\
\hline RTA-motor bike/cyclist & 0 & 0 & 6 & 27 & 6 & 0 & 39 & 6.1417 \\
\hline RTA driver & 0 & 0 & 0 & 28 & 10 & 0 & 38 & 5.984 \\
\hline Total & 0 & 2 & 43 & 189 & 67 & 19 & 320 & 50.394 \\
\hline Drowning & 0 & 1 & 33 & 48 & 6 & 7 & 95 & 14.961 \\
\hline $\begin{array}{l}\text { Blunt injury (head, chest, and abdomen)/ } \\
\text { assault }\end{array}$ & 0 & 1 & 2 & 36 & 9 & 0 & 48 & 7.559 \\
\hline Gunshot injury & 0 & 0 & 8 & 20 & 5 & 1 & 34 & 5.354 \\
\hline Hanging & 0 & 0 & 6 & 16 & 5 & 4 & 31 & 4.882 \\
\hline Trapped by falling object & 0 & 0 & 8 & 11 & 8 & 0 & 27 & 4.252 \\
\hline Incised wound (chops/stab) & 0 & 0 & 2 & 16 & 4 & 3 & 25 & 3.937 \\
\hline Burns & 0 & 1 & 2 & 7 & 3 & 1 & 14 & 2.205 \\
\hline Electrocution & 0 & 0 & 6 & 7 & 0 & 0 & 13 & 2.047 \\
\hline Poisoning & 0 & 0 & 0 & 5 & 3 & 1 & 9 & 1.417 \\
\hline Fall from height & 0 & 0 & 1 & 6 & 0 & 1 & 8 & 1.260 \\
\hline $\begin{array}{l}\text { Asphyxia due to entrapment by a falling tree, } \\
\text { wall, pit, vehicle, etc. }\end{array}$ & 0 & 0 & 1 & 1 & 1 & 0 & 3 & 0.472 \\
\hline Pathological fracture & 0 & 0 & 0 & 0 & 0 & 2 & 2 & 0.315 \\
\hline Snake bite & 0 & 0 & 1 & 1 & 0 & 0 & 2 & 0.315 \\
\hline Human bite & 0 & 0 & 0 & 0 & 0 & 1 & 1 & 0.158 \\
\hline Inhaled foreign body & 0 & 0 & 1 & 1 & 0 & 0 & 2 & 0.315 \\
\hline Smothering & 1 & 0 & 0 & 0 & 0 & 0 & 1 & 0.158 \\
\hline Total & 1 & 5 & 114 & 364 & 111 & 40 & 635 & 100 \\
\hline \multicolumn{9}{|l|}{ Infections } \\
\hline Pneumonia & 0 & 0 & 5 & 7 & 12 & 7 & 31 & 31.959 \\
\hline $\begin{array}{l}\text { Gastroenteritis, enterocolitis, and typhoid } \\
\text { enteritis }\end{array}$ & 1 & 0 & 6 & 7 & 3 & 1 & 18 & 18.557 \\
\hline $\mathrm{TB}$ & 0 & 0 & 0 & 6 & 5 & 2 & 13 & 13.402 \\
\hline Meningitis & 0 & 0 & 3 & 4 & 2 & 1 & 10 & 10.309 \\
\hline $\begin{array}{l}\text { Secondary peritonitis from bowel perforation, } \\
\text { and primary peritonitis }\end{array}$ & 0 & 0 & 1 & 2 & 2 & 0 & 5 & 5.155 \\
\hline Chronic glomerulonephritis & 0 & 0 & 0 & 2 & 1 & 0 & 3 & 3.093 \\
\hline Acute pyelonephritis & 0 & 0 & 0 & 2 & 1 & 0 & 3 & 3.093 \\
\hline Empyema thoracis & 0 & 0 & 1 & 0 & 0 & 1 & 2 & 2.062 \\
\hline Encephalitis & 0 & 0 & 0 & 2 & 0 & 0 & 2 & 2.062 \\
\hline HIV/AIDS & 0 & 0 & 0 & 2 & 0 & 0 & 2 & 2.062 \\
\hline Hepatitis B & 0 & 0 & 0 & 1 & 0 & 0 & 1 & 1.031 \\
\hline Endocarditis & 0 & 0 & 1 & 0 & 0 & 0 & 1 & 1.031 \\
\hline Alcoholic hepatitis & 0 & 0 & 0 & 0 & 1 & 0 & 1 & 1.031 \\
\hline Subdural abscess & 0 & 0 & 0 & 1 & 0 & 0 & 1 & 1.031 \\
\hline Septic arthritis & 0 & 0 & 1 & 0 & 0 & 0 & 1 & 1.031 \\
\hline Osteomyelitis & 0 & 0 & 0 & 0 & 1 & 0 & 1 & 1.031 \\
\hline Lung abscess & 0 & 0 & 0 & 0 & 1 & 0 & 1 & 1.031 \\
\hline Rabies & 0 & 0 & 1 & 0 & 0 & 0 & 1 & 1.031 \\
\hline Total & 1 & 0 & 19 & 36 & 29 & 12 & 97 & 100.000 \\
\hline
\end{tabular}

accounted for $80 \%$ of the deaths in road traffic accidents in Kenya [10]. In this study, drivers, passengers, and pedestrians made up $88 \%$ of victims. On their own, pedestrians formed the majority of victims of road traffic accidents. They accounted for $43 \%$ of all deaths from road traffic accidents. This is not different from a previous report in Ghana which indicated pedestrians were a vulnerable group and constituted more than $40 \%$ of the annual crash fatalities [11]. A similar situation pertains in Benin City, Nigeria, where of all road traffic accidents which were the commonest $(86.7 \%)$ cause of unnatural deaths in one study, motor vehicle drivers and their passengers formed $41.8 \%$; pedestrians, $37.1 \%$; and motorcyclists and their passengers, 18.6\% [9]. The high proportions of passenger fatalities observed in the present study appear to be associated with conditions stated in the Kenyan study "the extensive use of public transport, types and condition of such vehicles, and the driving skill of the operators of such public vehicles" [10]. Most of these deaths were in young adults aged 18-44 years (59\%), who play key roles in the tourism industry or are themselves tourists. This finding is not different from an earlier report in Ghana that $65.16 \%$ of the pedestrians killed in RTAs occurring in the period 2001-2011 were in the age range 1-40 years old [11]. Another report similarly stated that most fatalities during 
the study period occurred in victims who were $26-35$ years. In that study, the broad age group, 16-45 years, were the most vulnerable in road traffic fatalities, representing more than $60 \%$ of the total fatalities [12].

It has been suggested that in low-income countries, it appears that gross domestic product (GDP)/capita growth is associated with a rise in traffic deaths [13]. This suggests that unless preventative action is taken, deaths due to road traffic accidents will rise as Ghana's GDP/capita growth increases until the country reaches higher income status. Traffic crashes have however been reported to impact the economy of developing countries at an estimated cost of $1-2 \%$ of a country's gross national product per annum, as a result of morbidity, mortality, and property-related costs [13]. Some studies report that globally, about "US $\$ 518$ billion is spent on road traffic crashes with low- and middle-income countries accounting for US $\$ 65$ billion-more than these countries receive in development assistance" [13]. Locally, previous studies have reported that the estimated gross domestic product (GDP) lost due to road crashes in Ghana was $1.6 \%$ valued at US\$419 million [14]. In the absence of a reliable and safe public transport system, tourists to the Central Region will continue to rely on available means of transport resulting in their exposure to the high risk of RTAs.

Elsewhere, the potential negative effects of this level of road traffic accidents on tourism is highlighted in a study of 794 German tourists who travelled to Kenya, Tanzania, Senegal, the Gambia, India, Nepal, Thailand, or Brazil; the study showed that more than $5 \%$ experienced an accident [15]. Another study showed that from 2004 to 2006, there were 2,361 deaths of US citizens overseas due to injury and that $37.8 \%$ of US citizen injury deaths in the low-to middleincome Americas were due to vehicle crashes [15]. The study encourages US citizens to be aware of regional variation of injury deaths in foreign countries, especially for motor vehicle crashes, drowning, and violence [15].

It is worth noting that in our study, in the category of accidents, injuries, and poisoning, deaths due to road traffic accidents were followed by deaths due to drowning (14.96\%), gunshots $(5.35 \%)$, and hanging (4.88\%). Most of the economic activities including tourism in the Central Region center on the beaches and other water bodies. Unsafe beaches and water bodies are likely to have a negative effect on economic activity in the region. The unnatural causes of death in this study are similar to those found in the American study [15]. The economic effects of these unnatural deaths have been demonstrated in some studies. However, the exact economic relationship between unnatural deaths and tourism in the Central Region remains to be studied.

The top five infectious causes of death were in decreasing order of frequency: community-acquired pneumonia (31.96\%), gastroenteritis, enterocolitis and typhoid enteritis $(18.56 \%)$, pulmonary tuberculosis $(13.40 \%)$, pyogenic meningitis and tuberculous meningitis (10.31\%), and generalized peritonitis from typhoid perforations (5.16\%). These infections are easily acquired in the community, due in some cases to poor sanitation and contaminated water sources. In addition, pulmonary tuberculosis is easily spread through air droplets and for foreign tourists who may not have received the BCG vaccine at birth, this may be a cause for concern. Though the cases of meningitis were not epidemic in nature, their numbers underscore the need to study their pattern and epidemiology, lest there is an epidemic with its widespread negative effects on both locals and foreigners. The high number of deaths due to gastroenteritis/enterocolitis and an annual cholera outbreak point to the poor state of hygiene in the Central Region. This is further confirmed by the still high number of typhoid enteritis/perforations, a disease transmitted through the orofecal route. The economic cost to food vendors and to medical insurance, both Ghanaian and foreign whenever there is an outbreak of cholera or when tourists have "traveler's diarrhea," is immense. Some studies have calculated the economic loss due to travelers' diarrhea [16]. It is important that steps are taken to improve sanitation and also to reduce the burden of infections in the Central Region.

In this study, $52.63 \%$ of the victims were young adults (18-44 years) followed by the middle-aged (45-64 yrs) (23.54\%), elderly people (45-65 years) $(7.88 \%)$, and then by children (13 months-17 years) $(15.05 \%)$. This is in agreement with reports that worldwide, "at the population level, premature mortality accounts for approximately two-thirds to three-fourths of the national burden of disease, with developing countries experiencing higher levels of premature mortality" underscoring the need for accurate and complete data on mortality, by age, sex, and cause [5]. In this study, the leading age groups within which deaths occur are the most economically productive force of the region. The economic effect of this is immense considering that individuals in this age group are the main people involved in economic activities including tourism. However, in order to improve the health outcomes of individuals in this age group, it is important that accurate civil and vital health statistics are collected and collated to enable the right policies to be implemented. This relationship has been demonstrated in previous publications that suggest that optimally functioning civil registration and vital statistics systems are independently and statistically significantly associated with better health outcomes [17].

\section{Conclusion}

The leading causes of death in the communities of the Central Region are road traffic accidents, infections, and drowning. These deaths occur most commonly in economically active young adults. The trend is likely to have a negative effect on economic activity and on tourism. There is the need to reduce the burden of road traffic accidents, infections, and drowning in the Central Region. In order to derive accurate and complete data from our current civil registration and vital statistics system, there is the need for proper assessment of the system and for data quality evaluation according to a standard framework that identifies gaps in current data capture and compilation from the community. 


\section{Data Availability}

Data for this publication can be obtained from the corresponding author once he is notified.

\section{Conflicts of Interest}

The authors declare that they have no conflicts of interest.

\section{References}

[1] P. K. Akakpo, A Guide to Autopsy Practice in Ghana, Icon Publishing, Accra, Ghana, 2015.

[2] A. D. Lopez, D. McLaughlin, and N. Richards, "Reducing ignorance about who dies of what: research and innovation to strengthen CRVS systems," BMC Medicine, vol. 18, no. 1, p. $58,2020$.

[3] Document on the Internet, https://www.cdc.gov/globalhealth/ countries/ghana/pdf/Ghana_Factsheet.pdf.

[4] "Ghana statistical service 2010 population and housing census document on the internet," 2020, https://www.statsghana.gov. gh/gssmain/fileUpload/pressrelease/Mortality_in_Ghana.pdf.

[5] D. Cobos Muñoz, D. de Savigny, R. Sorchik et al., "Better data for better outcomes: the importance of process mapping and management in CRVS systems," BMC Medicine, vol. 18, p. 67, 2020.

[6] A. D. Lopez, D. McLaughlin, and N. Richards, "Reducing ignorance about who dies of what: research and innovation to strengthen CRVS systems," BMC Medicine, vol. 18, p. 58, 2020.

[7] C. Rao, "Elements of a strategic approach for strengthening national mortality statistics programmes," BMJ Global Health, vol. 4, no. 5, Article ID e001810, 2019.

[8] C. N. T. Amakiri, E. E. U. Akang, P. U. Aghadiuno, and W. O. Odesanmi, "A prospective study of Coroner's autopsies in university college hospital, Ibadan, Nigeria," Medicine, Science and the Law, vol. 37, no. 1, pp. 69-75, 1997.

[9] J. U. Aligbe, W. O. Akhiwu, and S. O. Nwosu, "Prospective study of Coroner's autopsies in Benin city, Nigeria," Medicine, Science and the Law, vol. 42, no. 4, pp. 318-324, 2002.

[10] W. Odero, K. Meleckidzedeck, and P. M. Heda, "Road traffic injuries in Kenya: magnitude, causes and status of intervention," Injury Control and Safety Promotion, vol. 10, no. 1-2, pp. 53-61, 2003.

[11] A. Coleman, "Road traffic accidents in Ghana: a public health concern, and a call for action in Ghana, (and the sub-region)," Open Journal of Preventive Medicine, vol. 4, no. 11, pp. 822828, 2014.

[12] T. Amo and S. Meirmanov, "The epidemiology of road traffic accident (RTA) in Ghana, 2001-2011," Life Science Journal, vol. 11, pp. 269-275, 2014.

[13] D. Bishai, A. Quresh, P. James, and A. Ghaffar, "National road casualties and economic development," Health Economics, vol. 15, no. 1, pp. 65-81, 2006.

[14] M. Peden, "Global collaboration on road traffic injury prevention," International Journal of Injury Control and Safety Promotion, vol. 12, no. 2, pp. 85-91, 2005.

[15] D. J. Tonellato, C. E. Guse, S. W. Hargarten, and S. W. Hargarten, "Injury deaths of US citizens abroad: new data source, old travel problem," Journal of Travel Medicine, vol. 16, no. 5, pp. 304-310, 2009.

[16] M. Wang, T. D. Szucs, and R. Steffen, "Economic aspects of travelers' diarrhea," Journal of Travel Medicine, vol. 15, no. 2, pp. 110-118, 2008.
[17] D. E. Phillips, C. AbouZahr, A. D. Lopez et al., "Are well functioning civil registration and vital statistics systems associated with better health outcomes?" The Lancet, vol. 386, no. 10001, pp. 1386-1394, 2015. 